\title{
PERAN SERTA PELAJAR DALAM PENEGAKAN HAK ASASI MANUSIA ATAS LINGKUNGAN HIDUP YANG BAIK DAN SEHAT DI SMA NEGERI I BAJUIN
}

\author{
Nurul Listiyani dan Ningrum Ambarsari \\ Program Studi Ilmu Hukum, Universitas Islam Kalimantan \\ Muhammad Arsyad Al Banjari Banjarmasin \\ Email : nurullistiyani5@gmail.com
}

\begin{abstract}
Based on the situation analysis and the inventory problems, the main purpose of this Public Service is to increase the students' legal awareness in order that the students are aware of their right on a good and healthy environment, and able to understand the importance of their participation as a form of the right and obligations in taking care of the living environment in order to stay sustainable.

Remembering about the pollution and damage of living environment which is happening in Indonesia, especially in Kecamatan Bajuin, Tanah Laut, then this Public Service activity is expected will decrease the occurrence of the pollution and damage of living environment, by the increasing of the students' awareness towards their right on a good and healthy environment. By using draft action, it is expected that this public service will be able to produce the students' legal awareness towards their right on a good and healthy environment which is every citizen's constitutional rights, so that the students will be active in participating as Indonesian citizen in performing their obligations to take care, conserve, and protect the living environment.
\end{abstract}

Keywords: participation, the students, human rights, living environment

\section{PENDAHULUAN}

Secara faktual, Bajuin semula terkenal karena obyek wisata air terjun yang ada di wilayah tersebut, yakni air terjun Bajuin. Bajuin sendiri merupakan sebuah kecamatan di Kabupaten Tanah Laut, Provinsi Kalimantan Selatan. Kecamatan ini dibentuk sebagai pemekaran dari Kecamatan Pelaihari berdasarkan Perda Nomor 2 Tahun 2008. Dengan luas wilayah $196,3 \mathrm{~km}^{2}$, Bajuin dihuni oleh sekitar 17.462 penduduk. Mayoritas mata pencaharian masyarakat di Kecamatan Bajuin sebelumnya adalah sebagai petani karet. Mata pencaharian tersebut kemudian bergeser ketika perkebunan sawit mulai menjadi primadona di wilayah tanah laut.

Selain maraknya perkebunan sawit di daerah Bajuin yang berdampak terhadap mata pencaharian penduduk setempat, maka daerah Bajuin, tepatnya Desa Deladak merupakan wilayah yang 
memiliki sumber daya alam, yakni sumber daya emas. Akan tetapi penambangan yang dilakukan di daerah tersebut merupakan pertambangan konvensional oleh masyarakat setempat, yang dilakukan secara turun temurun.

Lingkungan hidup yang baik dan sehat merupakan salah satu hak asasi yang dimiliki oleh setiap manusia. Lingkungan hidup yang baik dan sehat mampu tercipta apabila setiap masyarakat, yang dalam hal ini adalah para remaja, sadar akan pentingnya peran mereka dalam menjaga dan melestarikan lingkungan hidup. Remaja adalah sosok orang yang memiliki usia masih tergolong sangat muda serta mempunyai masa depan yang masih panjang. Sebuah usia yang potensial dalam membangun dan menjaga lingkungan hidup yang kini semakin rusak.

\section{KHALAYAK SASARAN}

Khalayak sasaran dalam kegiatan pengabdian kepada masyarakat dengan tema Peran Serta Pelajar Dalam Penegakan HAM atas Lingkungan Hidup yang Baik dan Sehat adalah siswa-siswa SMAN I Bajuin.

SMA Negeri 1 Bajuin merupakan sekolah tingkat atas satu-satunya di daerah pemekaran Bajuin. SMA ini mulai beroperasional pada tahun 2014 dengan jumlah murid angkatan pertama hanya 12 orang. Saat ini, setelah 3 tahun berjalan, jumlah murid telah semakin bertambah, yakni sebanyak 140 orang dengan guru pengajar sebanyak 18 orang.

Rata-rata umur para murid di SMAN 1 Bajuin adalah berkisar antara 16-18 tahun. Rentang usia tersebut masuk dalam kategori usia produktif, di mana masa-masa ini perlu ditanamkan kesadaran akan hak dan kewajiban mereka sebagai masyarakat. Sebagai individu, mereka memiliki hak hakiki yang dimiliki oleh mereka sejak lahir ke dunia, di mana tersebut dilindungi oleh negara. Hak hakiki tersebut lebih familiar disebut dengan Hak Asasi Manusia.

\section{METODE}

Metode yang digunakan dalam kegiatan pengabdian adalah diawali dengan studi pendahuluan / identifikasi masalah. Dengan menggunakan rancangan aksi, diharapkan kegiatan pengabdian ini dapat menghasilkan kesadaran hukum para pelajar akan hak mereka atas lingkungan hidup yang baik dan sehat yang merupakan hak 
konstitusional setiap warga negara. Agar kegiatan pengabdian dapat berjalan efektif, efisiensi dan relevansi dapat terjamin, maka langkah-langkah kegiatan disusun melalui tahapantahapan sebagai berikut :

\section{Tahap I : mengidentifikasi permasalahan}

Pada tahap ini dilakukan identifikasi permasalahan di Kecamatan Bajuin sebagai salah satu wilayah penghasil sumber daya alam permasalahan tersebut kemudian disinkronkan dengan melihat gejala sosial yang ada di masyarakat Bajuin, yang dikerucut hanya terhadap para pelajar SMAN I Bajuin. Variabel yang akan diukur meliputi : usia, tingkat pendidikan, latar belakang keluarga, keperdulian terhadap ligkungan hidup.

Tahap II. Mengembangkan pola sosialisasi terhadap pelajar SMAN I

\section{Bajuin}

diawali dengan sosialisasi, yang bertujuan untuk saling mengenal (dengan tujuan pendekatan), memberikan informasi dan penyamaan persepsi tentang tema pengabdian kepada masyarakat, dengan langkah-langkah sebagai

berikut :

a. melakukan sosialisasi pada kelompok sasaran;

b. materi umum, diberikan untuk meningkatkan pengetahuan dari Dewan guru dan siswa-siswa SMAN I Bajuin;

c. materi penunjang, yang ditambahkan sebagai penunjang, meliputi : etika, kepribadian, komunikasi dan lain-lain.

d. Mengevaluasi hasil sosialisasi

\section{HASIL PELAKSANAAN KEGIATAN}

\section{A. Dasar Pemikiran}

Remaja adalah sosok orang yang memiliki usia masih tergolong sangat muda serta mempunyai masa depan yang masih panjang. Sebuah usia yang potensial dalam membangun dan menjaga lingkungan hidup yang kini semakin rusak. Dengan usia yang masih muda tersebut, sebenarnya penglibatan remaja dalam menjaga kelestarian alam dan lingkungan hidup sangatlah ideal. Oleh karena itu perlu disadari dan menjadi catatan bersama bahwa penglibatan remaja dalam melestarikan alam sejak masa remaja 
sangatlah penting dan sangat besar pengaruhnya bagi perkembangan lingkungan, sekarang dan yang akan datang.

Agar remaja bisa terlibat aktif dalam menjaga kelestarian alam dan lingkungan yang baik, remaja harus dibekali secara cukup tentang pengetahuan, kesadaran dan ketrampilan tentang bagaimana menjaga kelesatrian alam. Bila ini dilakukan sejak dini, kita yakin masa depan lingkungan dan kondisi alam bisa lebih baik ke depan.. Usianya yang masih sangat muda dapat memberikan suatu contoh yang baik dalam upaya penjagaan kebersihan dan kelestarian lingkungan. Dengan memulai dari suatu hal yang paling kecil, seperti membuang sampah pada tempatnya. Hal ini akan menciptakan lingkungan yang bersih. Apabila setiap remaja memiliki kesadaran diri dan rasa tanggung jawab pribadi untuk menjaga kebersihan lingkungan, kita yakin bahwa lingkungan hidup kita akan baik.

\section{B. Materi Pengabdian Kepada} Masyarakat

Kegiatan Pengabdian Kepada Masyarakat dilaksanakan di Kecamatan Bajuin, Kabupaten Tanah Laut, dengan khalayak sasaran siswa SMA Negeri I Bajuin. Dalam kegiatan tersebut, pengabdi menyampaikan materi yang memiiki keterkaitan erat dengan Hak Asasi Manusia atas lingkungan hidup yang baik dan sehat, dengan sub materi sebagai berikut:

a. Ciri khusus Hak Asasi Manusia

b. Pembagian Hak Asasi Manusia

c. Kewajiban Hak Asasi Manusia

d. Pelanggaran Hak Asasi Manusia

e. Penggolongan Pelanggaran Hak Asasi Manusia

f. Peran pelajar dalam pelestarian lingkungan hidup 


\section{Materi}

\section{CIRI-CIRI KHUSUS HAM}

Tidak dapat dicabut, artinya HAM

tidak dapat dihilangkan atau diserahkan
Tidak dapat dibagi, artinya semua orang berhak mendaptkan semua hak

Ciri khusus HAM dibandingkan hak lain

Universal, artinya HAM berlaku untuk semua orang tanpa memandang status, suku, bangsa, gender, atau perbedaan lainnya
Hakiki, artinya HAM semua umat manusia sudah ada sejak lahir

\section{MACAM-MACAM HAK ASASI MANUSIA}

- Kebebasan bepergian,
bergerak
- Mengeluarkan
pendapat
- Memilih dan
berorganisasi
Hak asasi
pribadi

- Mendapat perlakuan
yg sama dlm hukum \&
pemerintahan
- Mendapat layanan \&
perlindungan hukum
Hak asasi
hukum




\section{MACAM-MACAM HAK ASASI MANUSIA}

Click to add text

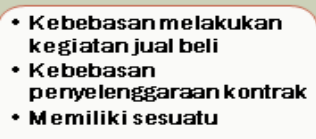

Hak asasi ekonomi
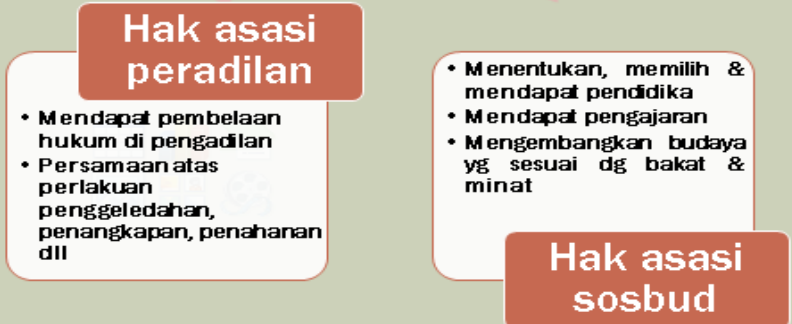

\section{KEWAJIBAN ASASI MANUSIA}

-Kewajiban manusia untuk menjalankan tugas manusia

-Kewajiban moral atas dasar norma benar dan salah sebagimana diterima dan diakui oleh masyarakat

-Kewajiban sosial atas dasar norma dan tingkah laku lingkungan sosial

-Kewajiban kepada Tuhan Sang Pencipta

\section{FAKTOR PENYEBAB TERJADINYA PELANGGARAN HAM}

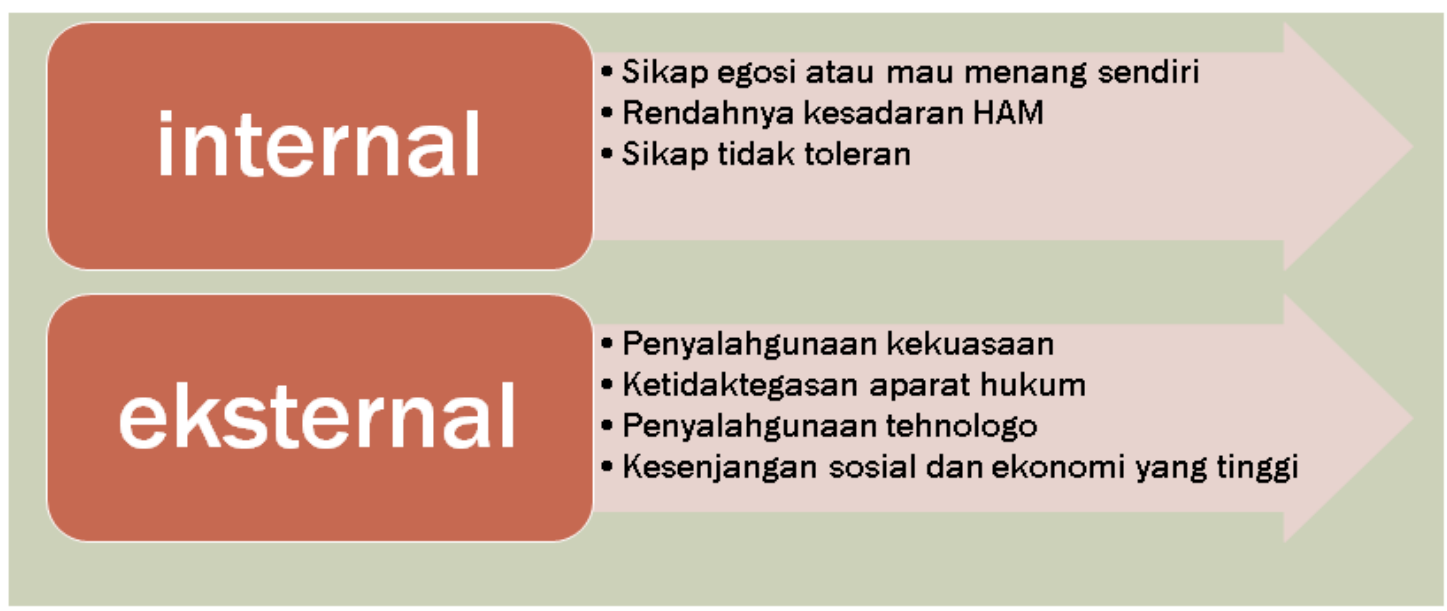




\section{PENGGOLONGAN PELANGGARAN HAM}
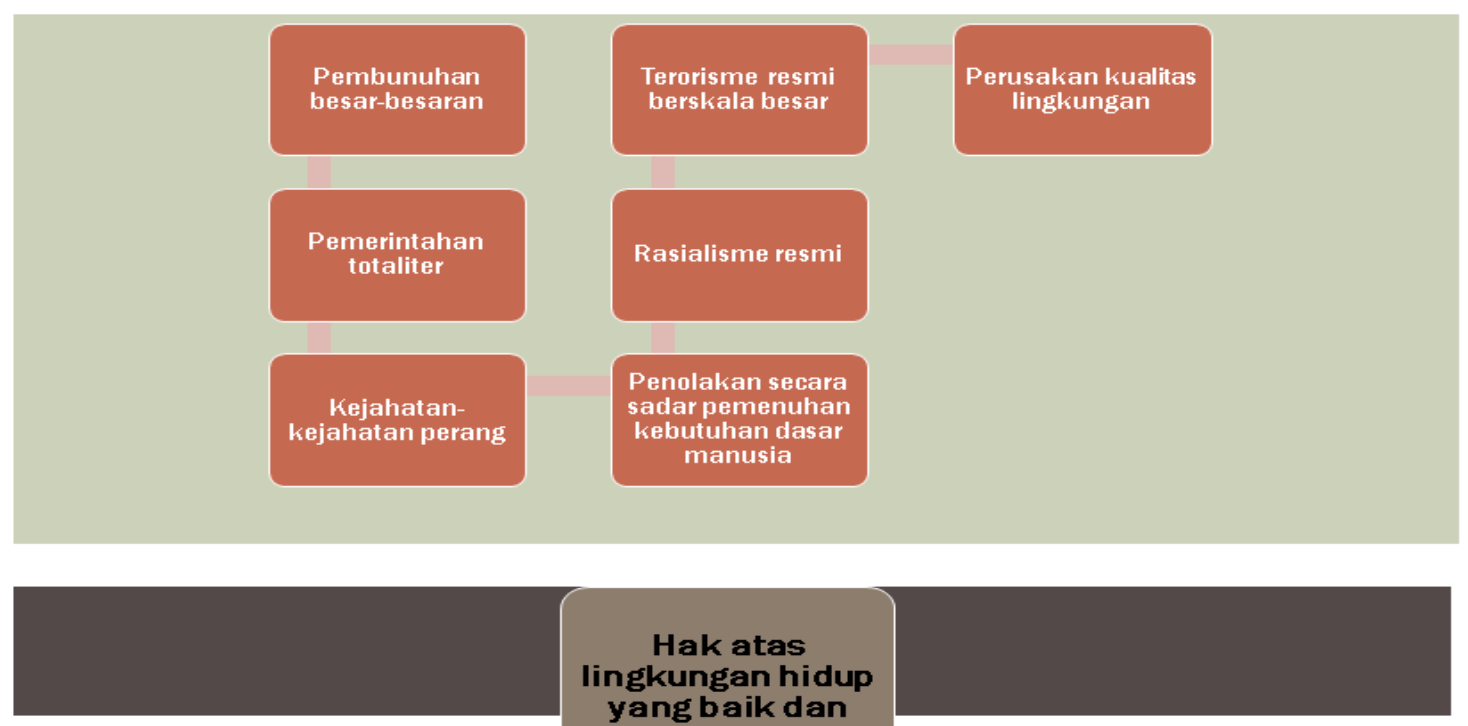

Hak atas lingkungan hidup

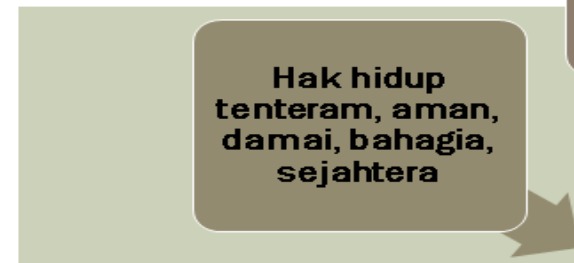
yang baik dan sehat
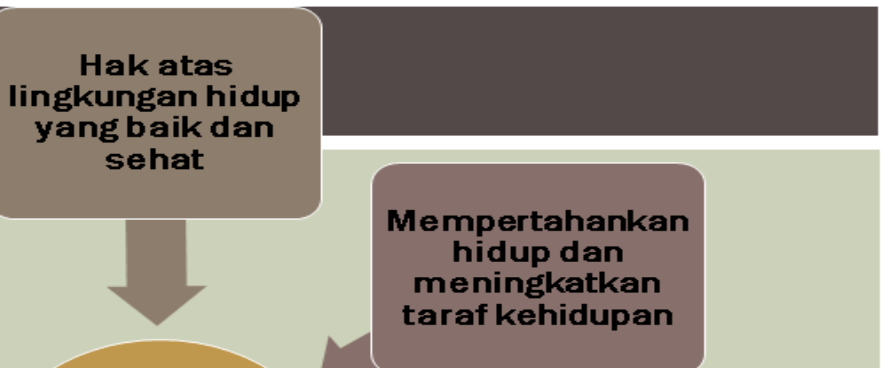

Mempertahankan hidup dan meningkatkan Hak hidup taraf kehidupan

\section{Pasal 9} (3) UU No. 39/1999

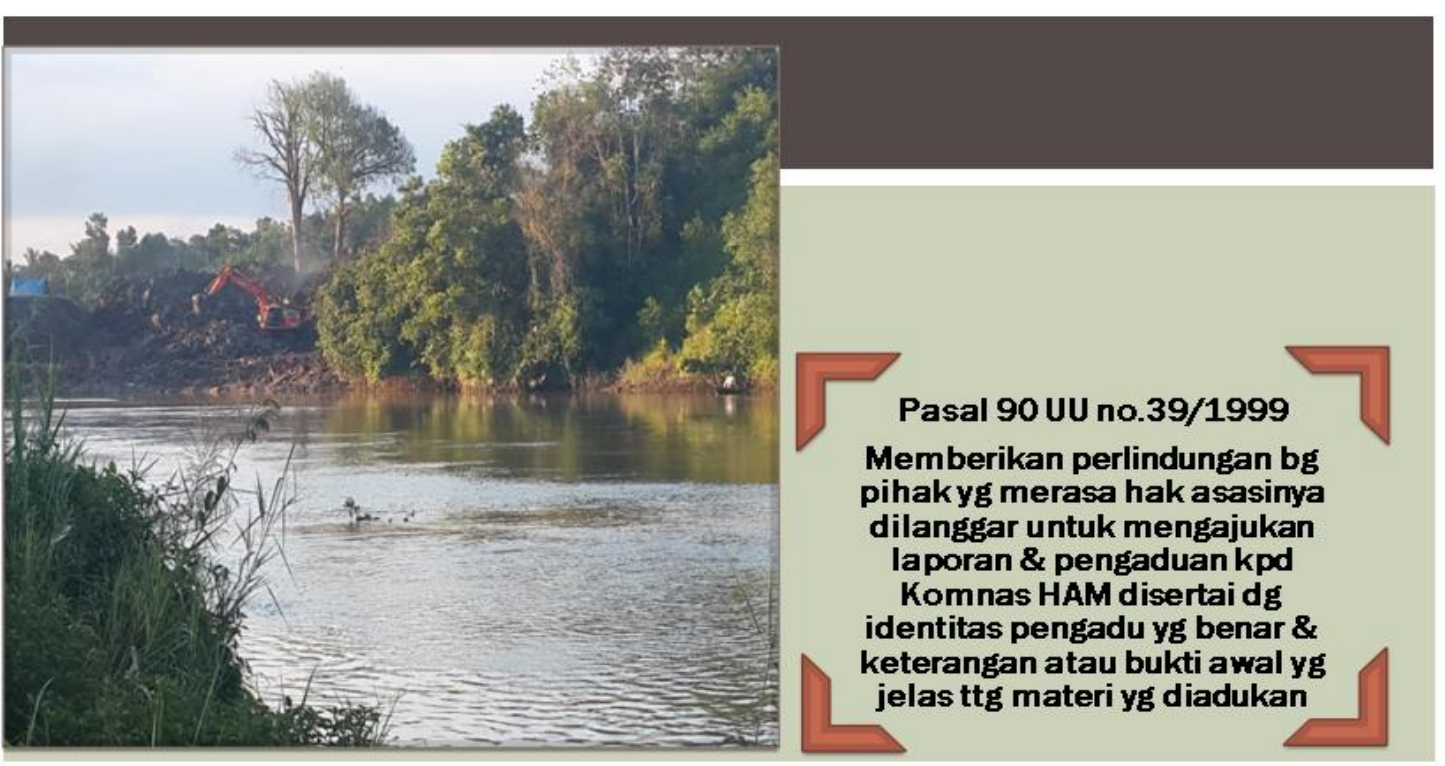


Melalui kegiatan sederhana

Membuang sampah pada tempatnya, tidak mencoretcoret dinding, giat berkebun

\section{Peran Pelajar dalam pelestarian lingkungan hidup}

Penyampaian informasi dan pengelolaan lingkungan hidup

\section{Pengawasan Sosial}

Pemberian saran, pendapat, usul, keberatan, pengaduan

\section{Evaluasi Pelaksanaan Pengabdian}

\section{Kepada Masyarakat}

Selama kegiatan penyuluhan hukum berlangsung, khalayak sasaran memberikan respon yang yang positif terhadap materi yang bertema "Peran Serta Pelajar dalam Penegakan Hak Asasi Manusia Atas Lingkungan Hidup yang Baik dan Sehat". Hal ini terbukti dari keaktifan siswa saat untuk berperan aktif dalam kegiatan, seperti memberikan pertanyaan, menyampaikan permasalahan yang berkaitan erat dengan lingkungan hidup, serta memberikan masukan terhadap peran mereka sebagai pelajar untuk melaksanakan penegakan HAM atas lingkungan hidup yang baik dan sehat.
Tim pengabdi melihat, bahwa materi yang disampaikan sangat tepat karena dari sisi penguasaan materi, dapat digeneralisir para siswa masih belum memahami secara mendalam bahwa setiap warga negara Indonesia memiliki hak asasi atas lingkungan hidup yang baik dan sehat. Hak asasi tersebut tentunya tidak boleh dilanggar maupun dicabut oleh siapapun juga.

\section{FOTO KEGIATAN}

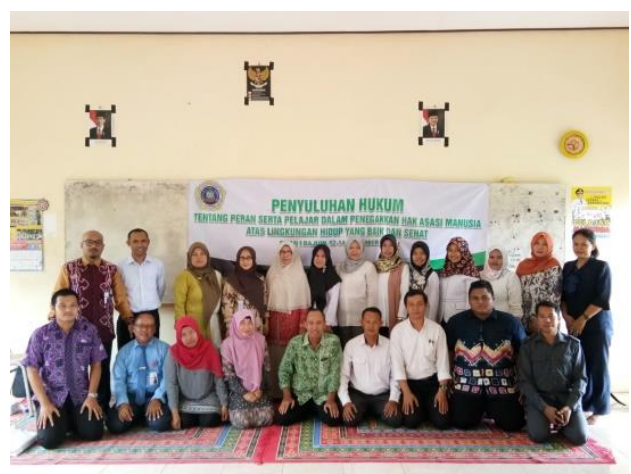



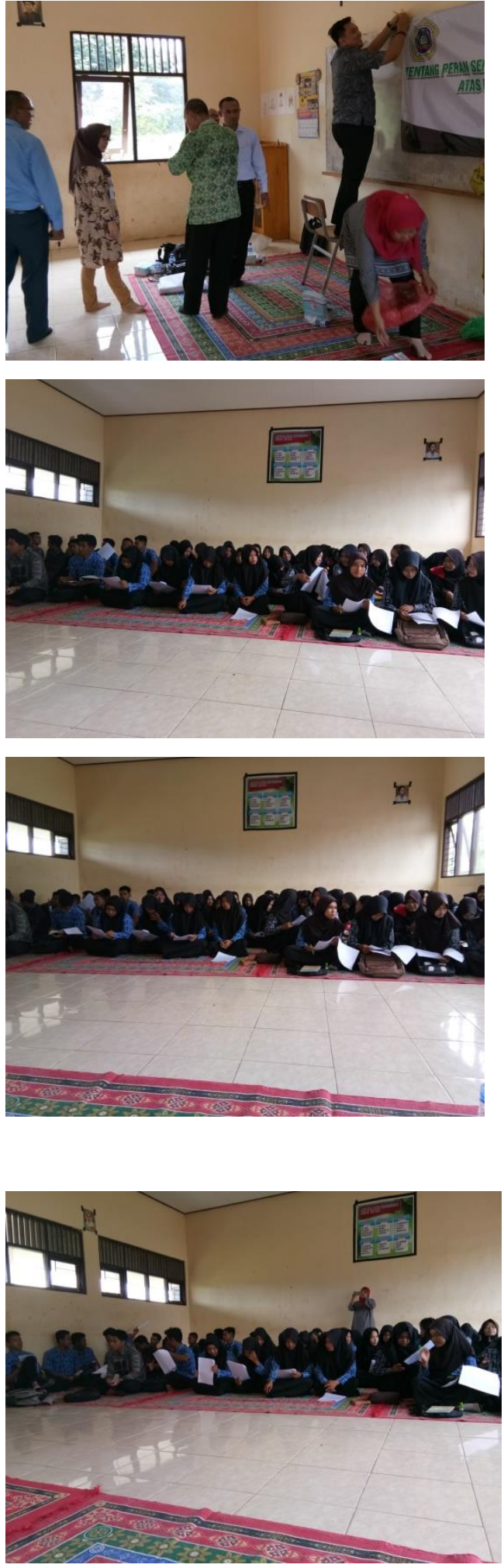

\section{KESIMPULAN}

Berdasarkan hasil kegiatan pengabdian kepada masyarakat dengan tema "Peran serta pelajar dalam penegakan hak asasi manusia atas lingkungan hidup yang baik dan sehat di SMA Negeri I Bajuin" maka diharapkan tujuan utama untuk meningkatkan kesadaran hukum para pelajar agar menyadari hak mereka atas lingkungan hidup yang baik dan sehat serta dapat memahami pentingnya peran serta pelajar sebagai bentuk hak dan kewajiban dalam menjaga lingkungan hidup agar tetap lestari dan berkelanjutan dapat tercapai.

Dengan tercapainya tujuan tersebut, maka selanjutnya diharapkan peran aktif warga masyarakat, khususnya para pelajar dalam menjaga dan melestarikan lingkungan hidup, akan dapat mengurangi pencemaran dan kerusakan lingkungan hidup yang terjadi di Indonesia, khususnya di Kecamatan Bajuin, Tanah Laut.

\section{DAFTAR PUSTAKA}

\section{Buku-buku :}

Asshiddiqie, Jimly. Green Constitution, Nuansa Hijau Undang-Undang Dasar Negara Republik Indonesia Tahun 1945. Jakarta: Rajawali Press. 2009

Listiyani, Nurul. Pengelolaan Lingkungan Hidup yang Berkelanjutan dalam 
$\begin{array}{llr}\begin{array}{l}\text { Pemanfaatan } \\ \text { Batubara. }\end{array} & \text { Sumber } & \text { Daya } \\ \text { Yogyakarta. } 2017 & \text { Buku. }\end{array}$

Rahmadi, Takdir. 2013. Hukum Lingkungan di Indonesia. Rajawali Pers. Jakarta

\section{Jurnal :}

Iskandar, Konsepsi dan Pengaturan Hak atas Lingkungan Hidup yang Baik dan Sehat (Kajian Perspektif HAM dalam Pengelolaan Lingkungan Hidup). Repository Universitas Bengkulu. 2011.

Gregorius, Junior B. Hak Asasi Manusia (HAM) Atas Lingkungan Hidup (Suatu Refleksi Sosio Yuridis Atas Implementasi Penyelesaian Sengketa Lingkungan). Jurnal Hukum dan
Pembangunan . Tahun ke-39 No.

3 Juli-September 2009.

Listiyani, N. (2017). Dampak Pertambangan Terhadap HakHak Warga Negara. Al Adl, 6784.

\section{Peraturan Perundang-Undangan}

Undang-Undang Dasar Negara

Republik Indonesia Tahun 1945;

Undang-Undang Nomor 23 Tahun 2014

tentang Pemerintah Daerah;

Undang-Undang Nomor 32 Tahun 2009 tentang Perlindungan dan Pengelolaan Lingkungan Hidup;

Undang-Undang Republik Indonesia Nomor 39 Tahun 1999 tentang Hak Asasi Manusia 